\section{- \\ US government works toward grid modernization}

\author{
https://gridmod.labworks.org
}

$T^{\mathrm{n}}$ he reliability, resiliency, and security of the electricity grid in the United States are easy to overlook because electricity is readily available with the flick of a switch. But the country's power grid, which has become a vital part of modern society, is not set up to meet the needs and challenges of the future. Initially designed to distribute electricity that was generated at large-scale and often remote facilities, the grid architecture included very little energy-storage capacity and operated with limited feedback and ability for control. Over the last century, there have been many changes that have impacted the grid-drastic growth, aging infrastructure, development and introduction of alternative electricity generation methods, deployment of efficiency measures, increasing cyber security threats, and climate impacts. The grid requires modernization to ensure electricity will continue to be available with the flick of a switch.

The Grid Modernization Initiative (GMI) is a US Department of Energy
(DOE) effort to update the country's grid. Based on ideas and recommendations found within the DOE's recent Quadrennial Energy Review (QER) and Quadrennial Technology Review (QTR), the GMI webpage says it brings together "public and private partners to develop the concepts, tools, and technology needed to measure, analyze, predict, protect, and control the grid of the future." The QER characterizes the electricity grid as a "critical and essential national asset" and makes the case for US government involvement in updating the grid saying, "it is a strategic imperative to protect and enhance the value of the electricity system through modernization and transformation."

Established under the Obama administration to build on grid modernization efforts supported by the American Recovery and Reinvestment Act of 2009, the GMI is a coordinated effort across the DOE. Within the GMI, the Grid Modernization Laboratory Consortium (GMLC) is a strategic partnership that was established between $14 \mathrm{DOE}$ laboratories (see Table 1) to streamline the grid modernization process by sharing expertise, resources, and technologies. In addition, the GMI released a Multi-Year Program Plan (MYPP) in 2016 that acts as a five-year roadmap by defining priorities and outlining grid-related research, development, and deployment activities for the DOE. The MYPP reiterates the need for US government involvement in updating the electricity grid saying, "The current business-as-usual trajectory for the electricity industry will not result in a timely transition to a modernized grid."

The modern grid envisioned by the GMI is detailed in the MYPP as follows:

- greater resilience to hazards of all types;

- improved reliability for everyday operations;

- enhanced security from an increasing and evolving number of threats;

- additional affordability to maintain our economic prosperity;

- superior flexibility to respond to the variability and uncertainty of conditions at one or more time scales, including a range of energy futures; and

- increased sustainability through additional clean energy and energy-efficient resources.

Awards for the first round of GMI funding within the GMLC were announced in January 2016. The DOE awarded 88 projects worth USD $\$ 220$ million over a three-year timespan. Each project is led by one or more GMLC laboratories, and several also partner with other federal agencies, state agencies, public utility commissions, and nongovernment entities including utilities and power producers, reliability organizations, technology developers and vendors, universities and research institutes, industry and professional associations, policy and regulatory associations, standards organizations, and testing companies. The funding supports research and development that has been described as critical to grid modernization and covers a variety of projects from advanced energy storage, to integration of clean energy, to standards and test procedures.

In April 2017, the GMI held an independent peer review where the results of the first 88 grid modernization projects were presented and 30 projects that were characterized as foundational to the initiative were formally reviewed. The 30 projects spanned six technical areas including devices and integrated systems; sensing and measurement; design and planning tools; system operations, power flow, and control; security and resilience; and institutional support. The feedback provided by the independent peer reviewers is being used to help reevaluate the 
projects and portfolio of the GMI and update the MYPP as needed.

The GMI's most recent round of funding was announced in September 2017. Up to USD \$32 million over three years was awarded to GMLC laboratories and their partners to address resilient distribution systems. The funded projects will focus on integrating clean distributed energy resources (DERs) into the grid, implementing real-time system monitoring, developing and testing advanced controls, and designing advanced cyber security technologies to apply to the grid. The results of these projects are expected to provide data that will help inform the decisions of both public and private investments in continuing grid modernization.

Materials scientists and engineers have played a significant role in making the current electricity grid obsolete while also leading the way to a cleaner and more energy efficient future. Through research that has enabled the deployment of a number of different clean DER technologies and the development of materials-based energy efficiency solutions, materials scientists have inadvertently raised new challenges for grid modernization. But at the same time, materials researchers are already playing a notable role in many GMI-supported projects to update the grid and accommodate these technologies by developing new materials and methods for energy conversion, transport, and storage. Undoubtedly, grid modernization will be a lengthy and challenging undertaking, but it is reassuring to see materials scientists and the US government working to move toward the reliability and resilience needed to keep the lights on across America.

Jennifer A. Nekuda Malik

\section{EC awards Paris as most innovative European city in 2017}

$\mathrm{T}^{\mathrm{s}}$ he European Commission (EC) awarded the 2017 European Capital of Innovation (iCapital) Prize of $€ 1,000,000$ to Paris, France.

The iCapital award, granted under the EU's research and innovation program Horizon 2020, recognizes Paris for its inclusive innovation strategy. Tallinn (Estonia) and Tel Aviv (Israel) were selected as runners-up, and were both awarded $€ 100,000$. The prize money will be used to scale up and further expand the innovation efforts of the cities.

Carlos Moedas, Commissioner for Research, Science and Innovation, said, "Cities are not defined by their size and population, but by the breadth of their vision and the power bestowed upon their citizens. Some cities are not afraid to experiment."

Over the last decade, Paris has built more than 100,000 square meters of incubators, and now hosts the world's largest startup campus. In addition, the city spends $5 \%$ of its budget on projects proposed and implemented by citizens. With this strategy, citizens and innovators from the private, nonprofit, and academic sectors have made Paris become a FabCity, according to the EC.

Through the "Reinventing Paris" project, the city facilitated innovation by inviting national and international talents to rebuild many of its significant sites.
In the current phase of the project the city is inviting interdisciplinary teams to submit innovative urban development projects for transforming a number of underground sites in Paris.

Tallinn has been awarded for its initiative to act as a testing ground for potential breakthrough technologies. The municipality fostered the use of self-driving cars, parcel delivery robots, and ride-sharing. Tallinn has also implemented an innovative e-Residency system, which enables local citizens and businesses to work closely together with foreign entrepreneurs.

Tel Aviv has set up a Smart City Urban Lab that links up innovative startups with leading technology companies in order to facilitate breakthrough innovations for solving urban challenges. Education being among Tel Aviv's priorities, part of the prize will be dedicated to strengthening the Smart Education Initiative, developed by the municipality in collaboration with teachers, parents, students, and local tech startups.

The 2017 iCapital award competition was launched in March 2017 for cities with over 100,000 inhabitants from EU Member States and countries associated with Horizon 2020. Thirtytwo cities from 17 countries applied to this year's competition. The winner and the two runners-up have been selected from 10 finalists on the basis of new initiatives launched since January 1, 2016. The winners were chosen by a panel of independent experts coming from universities and the business sector. The evaluators were selected from the Horizon 2020 expert database.

The award criteria focused on cities that are willing to be test beds for new citizen-driven initiatives to find solutions for their relevant societal challenges.

The competition first took place in 2014. That year, the prize $(€ 500,000)$ was awarded to Barcelona (Spain). Among the city's innovations were sustainable city growth initiatives on smart lighting, mobility (e-vehicle), and residual energy (heating and cooling networks).

Last year, Amsterdam (The Netherlands) received the award (€950,000) for "embracing a bottom-up approach based on smart growth, startups, livability, and digital social innovation." The runners-up were Paris "for its strategy based on open innovation, connectivity and ingenuity aiming at becoming a world hub for startup," and Turino (Italy) "for its open innovation models supporting social innovation startups and creating new market opportunities for urban innovations."

The awards are granted under Horizon 2020, the EU's research and innovation framework program with a budget of $€ 77$ billion over seven years (20142020). The competition for the 2018 iCapital is due to be launched in the first quarter of 2018 . 